\title{
COMPOSIÇÃO E DISTRIBUIÇÃO DA ARBORIZAÇÃO VIÁRIA DA ESTÂNCIA DE ÁGUAS DE SÃO PEDRO-SP
}

\author{
Silvana Bortoleto ${ }^{1}$, Demóstenes Ferreira da Silva Filho², Vinícius Castro Souza ${ }^{3}$, Marcelo
} Antonio de Pinho Ferreira ${ }^{4}$, Jefferson Lordello Polizel ${ }^{5}$, Roberval de Cássia Salvador Ribeiro ${ }^{6}$

\section{RESUMO}

O presente trabalho é referente ao levantamento das espécies contidas na arborização viária da Estância de Águas de São Pedro-SP e sua distribuição. Para isso, foram inventariados todos os indivíduos ocorrentes nas vias públicas; o que totalizou 3.654 indivíduos. Destes, 70,85\% são árvores, 19,90\% arbustos, 6,05\% palmeiras e 3,20\% coníferas; perfazendo 161 espécies, 126 gêneros e 54 famílias; sendo 61,33\% das espécies exóticas e 38,67\% nativas. O índice de diversidade de Odum (d) calculado é de 19,50 e o índice de Shanon-Wiener (H) é de 3,90. Na Estância de Águas de São Pedro encontrou-se uma predominância da Caesalpinia pluviosa (sibipiruna) que representa 13,66\% da arborização viária. A densidade média de indivíduos por quilômetro de rua percorrida é de 130. Conclui-se que a diversidade da arborização viária da Estância de Águas de São Pedro deve ser incrementada, o uso da flora nativa deve ser incentivado e a tendência de plantio de espécies arbustivas deve ser revertida; visando a sustentabilidade dessa arborização e consequentemente os benefícios ambientais proporcionados a população.

Palavras-chave: Árvores, Inventário, Urbanização.

\footnotetext{
${ }^{1}$ Engenheira Agrônoma, Departamento de Produção Vegetal, ESALQ/USP, Piracicaba-SP, silvana@esalq.usp.br.

${ }^{2}$ Engenheiro Agrônomo, Laboratório de Silvicultura Urbana, ESALQ/USP, Piracicaba-SP.

${ }^{3}$ Biólogo, Laboratório de Sistemática, ESALQ/USP, Piracicaba-SP.

${ }^{4}$ Engenheiro Florestal, Laboratório de Sistemática, ESALQ/USP, Piracicaba-SP.

${ }^{5}$ Analista de Sistema, Laboratório de Silvicultura Urbana, ESALQ/USP, Piracicaba-SP.

${ }^{6}$ Engnheiro Agrônomo, Laboratório de Produção Vegetal, ESALQ/USP, Piracicaba-SP.
} 


\title{
COMPOSITION AND DISTRIBUTION OF GREENERY (ARBORIZATION) ON THE STREETS OF ÁGUAS DE SÃO PEDRO RESORT - SP - BRAZIL
}

\begin{abstract}
This paper consists of an analysis of greenery (arborization) on the streets of the municipal district of Águas de São Pedro Resort, in São Paulo State, Brazil and its distribution. A census-type inventory was used in this research; therefore, all individuals planted on street sidewalks have been assessed. A total of 3,654 individuals were analyzed, comprising 161 species, 126 genera and 54 families. A total of $61.33 \%$ species were exotic whilst $38.67 \%$ were native; $70.85 \%$ were classified as trees, $19.90 \%$ as shrubs, 6.05 as palms and $3.20 \%$ as conifers. The $(\mathrm{d})$ diversity index was 19.50 and the $(\mathrm{H})$ was found to be 3.90 . A discreet predominance of Caesalpinia peltophoroides was observed, which represented $13.36 \%$ of street greenery. The average index of trees per kilometer of street was 130. It follows that the diversity of street greenery in the municipal district of Águas de São Pedro Resort should be improved; the use of native trees should be encouraged and the trend of planting shrubs instead of trees should be reversed, for the sustentability of this arborization, proportionate the ambient benefits to the population.
\end{abstract}

Key words: Trees, Survey, Urban. 


\section{INTRODUÇÃO}

O efeito da urbanização acelerada tem provocado grandes modificações sobre a paisagem. Toda essa ação antrópica causa danos drásticos, principalmente aos fragmentos remanescentes da vegetação, modificando seu ambiente natural (Alvarez et al., 2003).

A degradação das florestas vem ocorrendo com freqüência nas diversas regiões do país, transformando grandes extensões de habitats em fragmentos expressivamente menores e isolados uns dos outros, o que causa invariavelmente uma redução na biodiversidade e, consequentemente, uma redução na segurança do ecossistema em ambientes urbanos (São Paulo, 2000; Silva Filho, 2002). O uso da vegetação, ao longo da malha urbana, constitui-se, assim, em uma forma de auxiliar na preservação do equilíbrio biológico (Santos \& Teixeira, 2001).

A arborização viária, formando corredores verdes, é um dos elementos vegetados dos ecossistemas urbanos capazes de integrar os remanescentes de áreas florestais, de áreas verdes e de espaços livres; conectando-os de forma a colaborar com a diversidade da flora e da fauna (Rachid, 1999; Paiva \& Gonçalves, 2002; Meneguetti, 2003), além de promover benefícios ambientais à população urbana.

Dessa forma, a vegetação assume benefícios comprovados, que vão desde a melhoria microclimática - por meio da diminuição da reflexão das radiações, do aumento da umidade atmosférica e da conseqüente amenização das temperaturas, passam pelos benefícios econômicos resultantes da valorização de propriedades, até o controle das poluições atmosférica, acústica e visual, os benefícios sociais e a ação benéfica à saúde humana física e mental (Milano \& Dalcin, 2000); além de interferir na direção e na velocidade do vento (Lombardo, 1990).

Visto isso, o presente trabalho apresenta um censo da arborização viária da Estância de Águas de São Pedro-SP, com o objetivo de avaliar sua diversidade, distribuição e composição das espécies dessa malha viária, a fim de oferecer subsídios para a manutenção e incremento dessa arborização.

\section{MATERIAL E MÉTODOS}

\section{Local de estudo}

O estudo foi realizado na Estância de Águas de São Pedro, município do Estado de São Paulo. Sua área total perfaz $3,9 \mathrm{~km}^{2}$ e sua localização apresenta as seguintes referências: entre $22^{\circ} 35$ '58“ latitude sul e 47ํ52 $34^{\prime \prime}$ " longitude oeste, fazendo divisa com o município de São Pedro em todo o seu perímetro. A Estância apresenta altitude de cerca de 
$470 \mathrm{~m}$ e um relevo de depressão, com temperatura média anual de $27,2^{\circ} \mathrm{C}$ e índice pluviométrico de 500 mm/ano (Águas de São Pedro, 2004).

Águas de São Pedro, como é também chamada, possui uma população urbana de 1.845 pessoas (Censo 2000-IBGE). A taxa de crescimento demográfico é de 4,06\% ao ano e a densidade demográfica é de 473,08 habitantes $/ \mathrm{km}^{2}$. A taxa de urbanização é de $100 \%$, não possuindo área rural. A economia local é alicerçada no turismo, que é a atividade preponderante no município, muito procurado principalmente por suas águas medicinais (Águas de São Pedro, 2004).

\section{Material de campo}

Os materiais utilizados em campo e com as respectivas finalidades, incluem: trena para medição de circunferência à altura do peito e hipsômetro Blume-Leiss para determinação da altura geral; caderno de planilhas para as anotações; jornal, papelão e barbante para confecção de exsicatas das espécies não identificadas in loco para posterior identificação pelo Departamento de Ciências Biológicas/ESALQ/ USP e aparelho Garmin GPS MAP-295 para georreferenciar a base cartográfica obtendo-se assim, os comprimentos das vias.

\section{Levantamento de informações}

Foram inventariados todos os indivíduos contidos em vias públicas na área total do município, excetuando-se as áreas verdes. Nessa etapa foram anotados e medidos dados referentes ao indivíduo como: número do indivíduo, com numeração crescente, contando também covas e indivíduos mortos; nome da rua; número do imóvel; nome comum; gênero; espécie; circunferência à altura do peito (CAP) (até nove bifurcações por indivíduo, quando o total de bifurcações ultrapassavam esse número, a circunferência era medida na área basal da planta, próxima ao solo) e a altura geral da copa.

\section{Análise dos dados}

Os dados foram tabulados em um banco de dados do Microsoft Access elaborado por Silva Filho (2002).

Para o georreferenciamento da base cartográfica da Estância de Águas de São Pedro, foi utilizado o TNT-Mips, onde foram medidos os comprimentos das vias públicas.

\section{RESULTADOS E DISCUSSÃO}




\section{Composição e distribuição das espécies}

No levantamento foram percorridos $30.176 \mathrm{~m}$ de ruas, avenidas e vielas, e analisados 3.654 indivíduos vivos.

Verificou-se que a espécie de maior prevalência observada é Caesalpinia pluviosa (sibipiruna), que constitui 13,63\% da arborização (Tabela 1).

Tabela 1. Distribuição quantitativa das espécies e variedades encontradas na arborização viária da Estância de Águas de São Pedro, segundo o total de indivíduos e a freqüência

\begin{tabular}{|c|c|c|c|}
\hline Nome Comum & Nome científico & Total & $\begin{array}{c}\text { Freqüência } \\
(\%)\end{array}$ \\
\hline Sibipiruna & Caesalpinia pluviosa Benth. & 498 & 13.63 \\
\hline Flamboyant & Delonix regia (Bojer ex Hook.) Raf. & 215 & 5.88 \\
\hline Ficus-benjamim & Ficus benjamina $\mathrm{L}$. & 186 & 5.09 \\
\hline Pata-de-vaca & Bauhinia variegata $\mathrm{L}$. & 158 & 4.32 \\
\hline Chapéu-de-sol & Terminalia catappa L. & 152 & 4.16 \\
\hline Hibisco & Hibiscus rosa-sinensis L. & 139 & 3.80 \\
\hline Areca-bambu & Dypsis lutescens H. Wendl. & 124 & 3.39 \\
\hline Oiti & Licania tomentosa (Benth.) Fritsch. & 99 & 2.71 \\
\hline Resedá & Lagerstroemia indica L. & 98 & 2.68 \\
\hline Espatódia & Spathodea nilotica Seem & 97 & 2.65 \\
\hline Falsa-murta & Murraya paniculata (L.) Jacq. & 86 & 2.35 \\
\hline *Ipê-roxo & Tabebuia sp. & 84 & 2.30 \\
\hline Chuva-de-ouro & Cassia fistula L. & 74 & 2.03 \\
\hline cerrado & Tabebuia chrysotricha (Mart. ex DC.) Stand. & 73 & 2.00 \\
\hline Quaresmeira & Tibouchina granulosa (Desc.) Cogn & 64 & 1.75 \\
\hline Mangueira & Mangifera indica $\mathrm{L}$. & 56 & 1.53 \\
\hline Pingo-de-ouro & Duranta repens L. & 55 & 1.51 \\
\hline Citrus & Citrus sp. & 53 & 1.45 \\
\hline Espirradeira & Nerium oleander L. & 52 & 1.42 \\
\hline Primavera & Bougainvillea spectabilis Willd. & 46 & 1.26 \\
\hline Tuia & Thuja occidentalis L. & 42 & 1.15 \\
\hline Pinos & Pinus elliotti Engel. & 41 & 1.12 \\
\hline Sabão-de-soldado & Sapindus saponaria $\mathrm{L}$. & 41 & 1.12 \\
\hline Tipuana & Tipuana tipu (Benth.) Kuntze & 41 & 1.12 \\
\hline Cróton & Codiaeum variegatum Blume & 37 & 1.01 \\
\hline Alfeneiro & Ligustrum lucidum W. T. Aiton & 35 & 0.96 \\
\hline Alecrim-de-campinas & Holocalyx balansae Mich. & 34 & 0.93 \\
\hline Falso-chorão & Schinus molle L. & 34 & 0.93 \\
\hline Ipê-branco & Tabebuia roseo-alba (Ridl.) Sandw. & 34 & 0.93 \\
\hline Goiabeira & Psidium guajava L. & 32 & 0.88 \\
\hline Pitangueira & Eugenia uniflora L. & 30 & 0.82 \\
\hline Magnólia-amarela & Michelia champaca L. & 29 & 0.79 \\
\hline Coqueiro-da-bahia & Cocos nucifera $\mathrm{L}$. & 28 & 0.77 \\
\hline Pau-brasil & Caesalpinia echinata Lam. & 27 & 0.74 \\
\hline Aroeira-pimenteira & Schinus terebinthifolius Raddi & 26 & 0.71 \\
\hline Ipê-rosa-americano & Tabebuia pentaphylla Hemsl. & 26 & 0.71 \\
\hline
\end{tabular}


Pata-de-vaca-branca Bauhinia variegata var. candida L. Grevilha Grevillea robusta A. Cunn. ex. R. Br.

Ficus-variegata

Amoreira

Ficus benjamina var. variegata $\mathrm{L}$.

$25 \quad 0.68$

Jaboticabeira

Morus nigra L.

Jasmim-manga

Myrciaria trunciflora Berg.

0.63

Plumeria rubra L.

23

$20 \quad 0.55$

Lanterna-japonesa

Koelreuteria elegans (Seem.) A.C.Sm.

0.52

Dracena roxa

Cordyline terminalis Kunth

0.52

Ipê-mirim

Palmeira-real

Tecoma stans (L.) Juss. Ex Kunth

0.52

Roystonea regia (H. B. K.) O. F. Cook

0.49

0.49

Lafoensia glyptocarpa Koehne

0.49

Mirindiba

Mussaenda erythrophylla Schum. \& Thonning

0.47

Mussaenda

Persea americana L.

0.47

Abacateiro

Thevetia peruviana K. Schum.

Chapéu-de-napoleão

Syagrus romanzoffiana (Cham.) Glassm.

Santa-bárbara

Melia azedarach L.

Acerola

Malpighia glabra L.

0.44

$16 \quad 0.44$

$16 \quad 0.44$

$16 \quad 0.44$

$15 \quad 0.41$

Pau-ferro

Caesalpinia ferrea var. leiostachya Benth Mart.

Cipreste-

mediterrâneo

ex Tul..

Cupressus sempervirens $\mathrm{L}$.

0.36

Nêspera

Eriobotrya japonica (Thunb.) Lind.

Flamboyant-de-jardim Caesalpinia pulcherrima Sw.

0.33

Palmeira-imperial

Roystonea oleracea (N. J. Jacquin) O. F. Cook

0.33

Livistonia chinensis (N. J. Jacquin) R. Brown ex

0.33

Palmeira-leque

Mart

Cabeça-de-velho

Euphorbia leucocephala Lotsy

0.27

Calabura

Muntingia calabura L.

Grevilha-anã

Grevillea banksii R. Br.

Leucena

Leucaena leucocephala (Lam.) R. de Wit

Manacá-de-jardim

Brunfelsia uniflora D. Don.

Pata-de-vaca-púrpura Bauhinia blakeana Dunn

Tuia-aurea

Thuja sp.

Astrapéia

Canelinha

Dombeya wallichii (Lindl.) K. Schum.

Paineira

Queureuteria

Nectandra megapotamica (Spreng.) Mez

Ceiba speciosa (A.St.-Hil.) Ravenna

Koelreuteria paniculata (Seem.) A.C.Sm.

Tuia-kaizuca

Palmeira-veitchia

Juniperus chinensis L.

Veitchia sp.

Ficus-microcarpa

Ficus microcarpa L.f.

Jambolão

Munguba

Peroba-rosa

Quaresmeira-

arbustiva

Romãzeiro

Araucária

Azaléia

Syzygium cumini (L.) Skeels

Pachira aquatica Aubl.

Aspidosperma polyneuron M. Arg.

0.25

0.25

0.25

0.25

0.22

0.22

0.22

0.19

0.19

0.19

0.19

0.19

0.16

0.14

$5 \quad 0.14$

$5 \quad 0.14$

$5 \quad 0.14$

Azeitona-do-ceilão

Tibouchina semidecandra (DC.) Cogn.

$\begin{array}{ll}5 & 0.14 \\ 5 & 0.14\end{array}$

Punica granatum L.

Araucaria columnaris (Forst.) Hook. $\quad 4 \quad 0.11$

Rhododendron simsii Planch. $\quad 4 \quad 0.11$

Elaeocarpus serratus $L$.

0.11

Schefflera arboricola (Hayata) Merr.

0.11 


\begin{tabular}{|c|c|c|c|}
\hline Esponja & Calliandra brevipes Benth. & 4 & 0.11 \\
\hline Ixora & Ixora coccinea $\mathrm{L}$. & 4 & 0.11 \\
\hline Mamoeiro & Carica papaya L. & 4 & 0.11 \\
\hline Tamarindo & Tamarindus indica L. & 4 & 0.11 \\
\hline Camelia & Camellia japonica L. & 3 & 0.08 \\
\hline Dama-das-noites & Cestrum intermedium Sendt. & 3 & 0.08 \\
\hline Dedaleira & $\begin{array}{l}\text { Lafoensia pacari St. Hil. } \\
\text { Callistemon viminalis (Sol. ex. Gaertn.)G. Don ex }\end{array}$ & 3 & 0.08 \\
\hline Escovinha-de-garrafa & Loud. & 3 & 0.08 \\
\hline Eugenia & Eugenia sprengelli DC. & 3 & 0.08 \\
\hline Figueira & Ficus sp. & 3 & 0.08 \\
\hline Guaçatonga & Casearia sylvestris Sw. & 3 & 0.08 \\
\hline Guanandi & Calophyllum brasiliene Camb. & 3 & 0.08 \\
\hline Jacarandá-branco & Platypodium elegans Vog. & 3 & 0.08 \\
\hline Jamelão & Syzygium jambos (L.) Alston & 3 & 0.08 \\
\hline Jequitibá-rosa & Cariniana legalis (Mart.) Kuntze & 3 & 0.08 \\
\hline Leiteira-roxa & Euphorbia cotinifolia L. & 3 & 0.08 \\
\hline Lofântera & Lophanthera lactescens Ducke & 3 & 0.08 \\
\hline $\begin{array}{l}\text { Palmeira rabo-de- } \\
\text { peixe }\end{array}$ & Caryota urens L. & 3 & 0.08 \\
\hline $\begin{array}{l}\text { Pata-de-vaca-do- } \\
\text { mato }\end{array}$ & Bauhinia forficata Link & 3 & 0.08 \\
\hline Sirigüela & Spondias purpurea $\mathrm{L}$. & 3 & 0.08 \\
\hline Sombreiro & Clitoria fairchildiana R. A. Howard & 3 & 0.08 \\
\hline Acácia & Acacia mangium Willd. & 2 & 0.05 \\
\hline Bananeira & Musa sp. & 2 & 0.05 \\
\hline Braúna & Melanoxylon brauna Schott & 2 & 0.05 \\
\hline Canafístula & Peltophorum dubium (Spreng.) Taub. & 2 & 0.05 \\
\hline $\begin{array}{l}\text { Castanha-do- } \\
\text { maranhão }\end{array}$ & Bombacopsis glabra (Pasq.) A. Rob. & 2 & 0.05 \\
\hline Chorão & Salix babylonica $\mathrm{L}$. & 2 & 0.05 \\
\hline Cicas & Cycas circinalis $\mathrm{L}$. & 2 & 0.05 \\
\hline Clerodendron & Clerodendron sp. & 2 & 0.05 \\
\hline Dama-da-noite & Cestrum nocturnum $\mathrm{L}$. & 2 & 0.05 \\
\hline Melaleuca & Melaleuca leucadendron (L.) L. & 2 & 0.05 \\
\hline Mil-cores & Breynia nivosa Small & 2 & 0.05 \\
\hline Nogueira-de-iguape & Aleurites moluccana (L.) Willd. & 2 & 0.05 \\
\hline Pau-formiga & Triplaris americana $\mathrm{L}$. & 2 & 0.05 \\
\hline Fênix & Phoenix canariensis Hort. ex Chabaud & 2 & 0.05 \\
\hline Pinha & Annona squamosa L. & 2 & 0.05 \\
\hline Sena & Senna macranthera (Collad.) Irwin et Barneby & 2 & 0.05 \\
\hline Tamareira-anã & Phoenix roebelenii O`Brien & 2 & 0.05 \\
\hline Tento-carolina & Adenanthera pavonina L. & 2 & 0.05 \\
\hline Uva-japonesa & Hovenia dulcis Thunb. & 2 & 0.05 \\
\hline Acacia-mimosa & Acacia podalyriifolia A. Cunn. ex G. Don & 1 & 0.03 \\
\hline Pinheiro-de-Kauri & Agathis robusta (C. Moore) F. M. Bailey & 1 & 0.03 \\
\hline Alamanda & Allamanda laevis Markgr. & 1 & 0.03 \\
\hline Erva-de-rato & Psychotria carthagenensis Jacq. & 1 & 0.03 \\
\hline Bico-de-papagaio & Euphorbia pulcherrima Willd. ex Klotzsch & 1 & 0.03 \\
\hline Bigueiro & Albizia lebbeck (L.) Benth. & 1 & 0.03 \\
\hline Brassaia & Schefflera actinophylla Harms & 1 & 0.03 \\
\hline
\end{tabular}




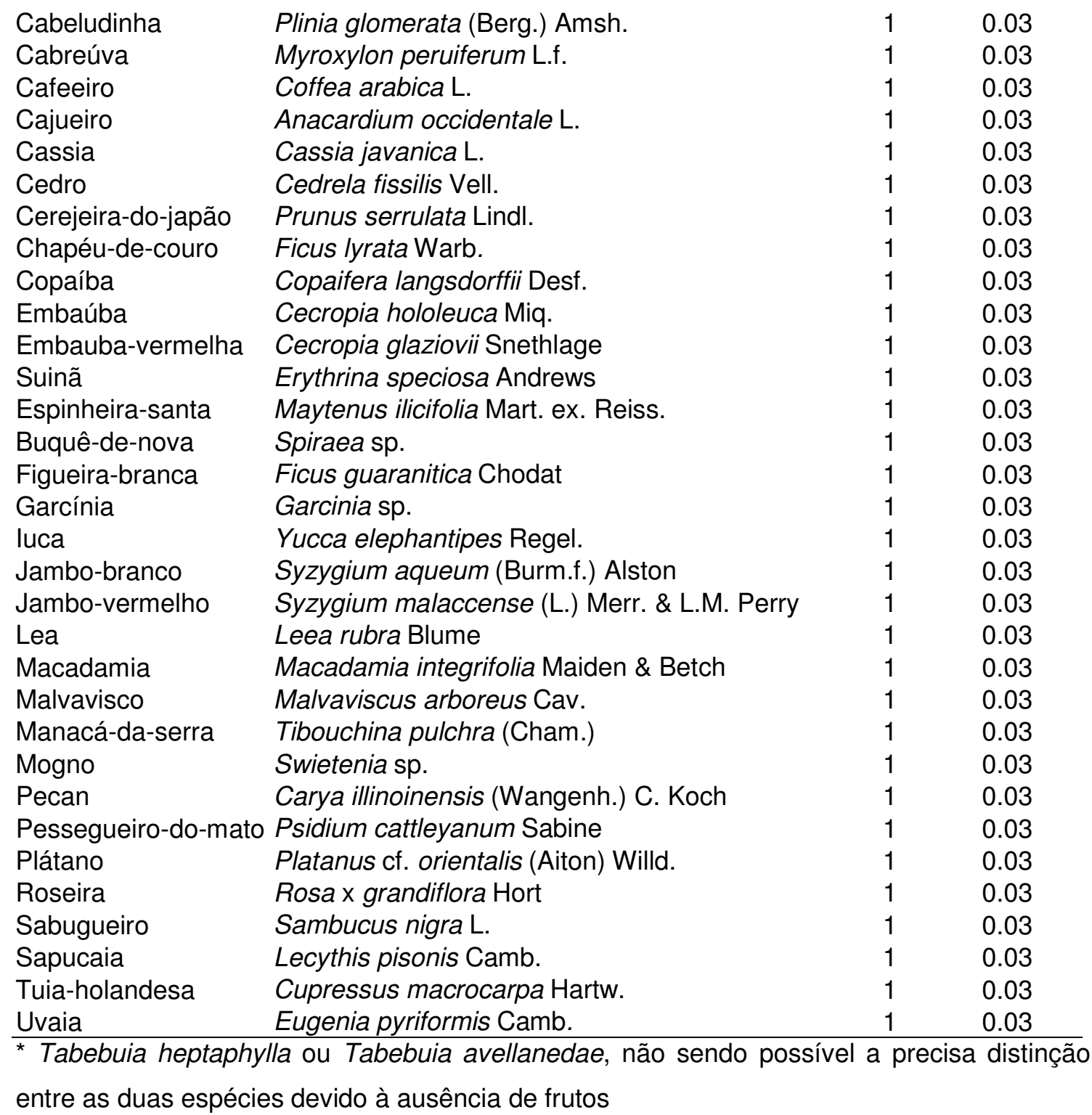

Segundo Santamour-Júnior (2002) uma grande diversidade de espécies de árvores na paisagem urbana se faz necessária justamente para garantir o máximo de proteção contra pragas e doenças, evitando assim, o aniquilamento de espécies, onde a arborização é muito homogênea. Dessa forma, segundo o mesmo autor, recomenda-se não exceder mais que $10 \%$ da mesma espécie, $20 \%$ de um mesmo gênero e $30 \%$ de uma família botânica. Na Estância de Águas de São Pedro observa-se apenas uma espécie que ultrapassa os $10 \%$ desejáveis, a sibipiruna (Tabela 1); quanto aos gêneros, não há nenhum com distribuição superior a $20 \%$ da arborização viária (Figura 1); o mesmo ocorre em relação às famílias, pois nenhuma representa mais que $30 \%$ da arborização viária (Figura 2). 


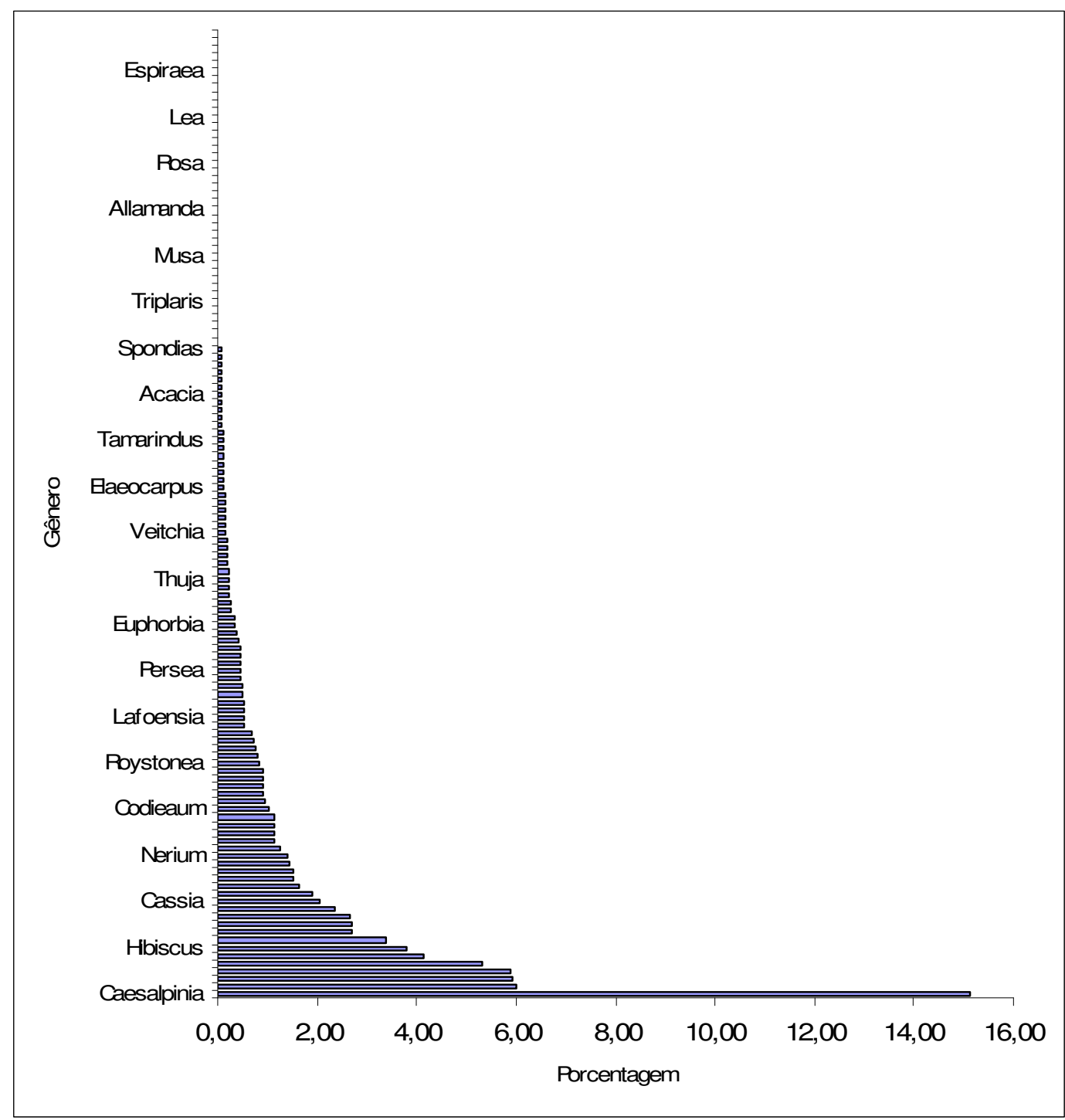

Figura 1 - Distribuição dos gêneros da arborização viária da Estância de Águas de São Pedro-SP 


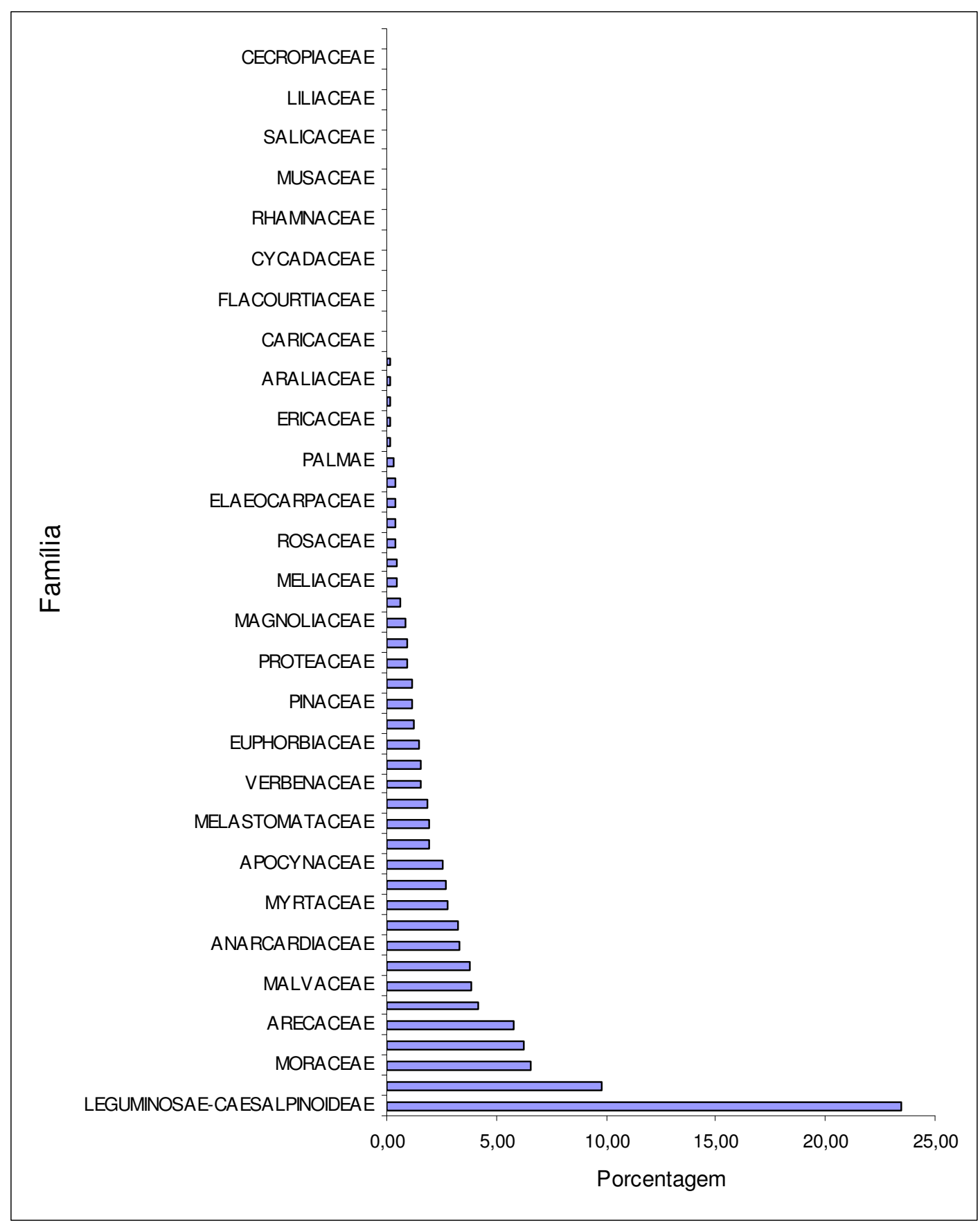

Figura 2 - Distribuição das famílias da arborização viária da Estância de Águas de São Pedro-SP

Foram contempladas 161 espécies, 126 gêneros e 54 famílias. A soma das porcentagens das dez espécies com maior freqüência correspondem a 48,33\% de toda a arborização viária, mostrando-se a necessidade de incrementos nessa diversidade, pois o desejável seria que nenhuma espécie ultrapassasse 10\%. 
Observou-se também, que 70,85\% das espécies levantadas são arbóreas, 19,90\% são arbustivas, 6,05\% são palmeiras e 3,20\% são coníferas; devendo-se atentar ao crescente uso de plantio de espécies arbustivas; pois se sabe que o microclima poderá ser rapidamente alterado, se essa tendência prevalecer (Paiva \& Gonçalves, 2002).

Calculou-se para a Estância de Águas de São Pedro uma densidade média de 130 indivíduos por quilômetro de rua percorrida, entre árvores, arbustos, palmeiras e coníferas. Essa alta densidade, no entanto, não caracteriza a Estância de Águas de São Pedro como possuidora de uma arborização viária bem planejada, pois ocorre elevada quantidade de espécies arbustivas (Tabela 1).

Na arborização viária da Estância Turística de Águas de São Pedro constatou-se a ocorrência de $61,33 \%$ de espécies exóticas e 38,67\% de espécies nativas do Brasil; sugerindo a necessidade de incentivo do uso da flora nativa.

A distribuição das espécies observadas nas vias públicas da Estância de Águas de São Pedro foi relacionada com classes de diâmetro à altura do peito (DAP), conforme Figura 3. Cada uma das espécies está representada com a quantidade de indivíduos cadastrados. Observa-se uma curva com tendência de queda conforme se aumenta a classe de DAP; apenas a classe de DAP maior que 0,61m mostra-se alta e esse fato se deve à inclusão de diversas classes acima deste valor. Nota-se uma relação direta entre a diversidade de espécies e a maior quantidade de indivíduos com as menores classes de DAP, revelando um número alto de plantios recentes, com uma maior diversidade de espécies. Pode-se afirmar que as menores classes de DAP são realmente mudas, pois os arbustos não recebem poda de condução e tiveram o DAP medido em sua base, ou seja, apresentaramse extremamente ramificados, conforme sua idade. Observa-se ainda que conforme a classe de DAP aumenta, diminui a diversidade de espécies, ou seja, certas espécies se estabelecem e se estabilizam nessa arborização. Nota-se também um aumento de plantio de espécies arbustivas, o que se traduzirá, futuramente, em menor conforto ambiental ao município, se nada for alterado. 


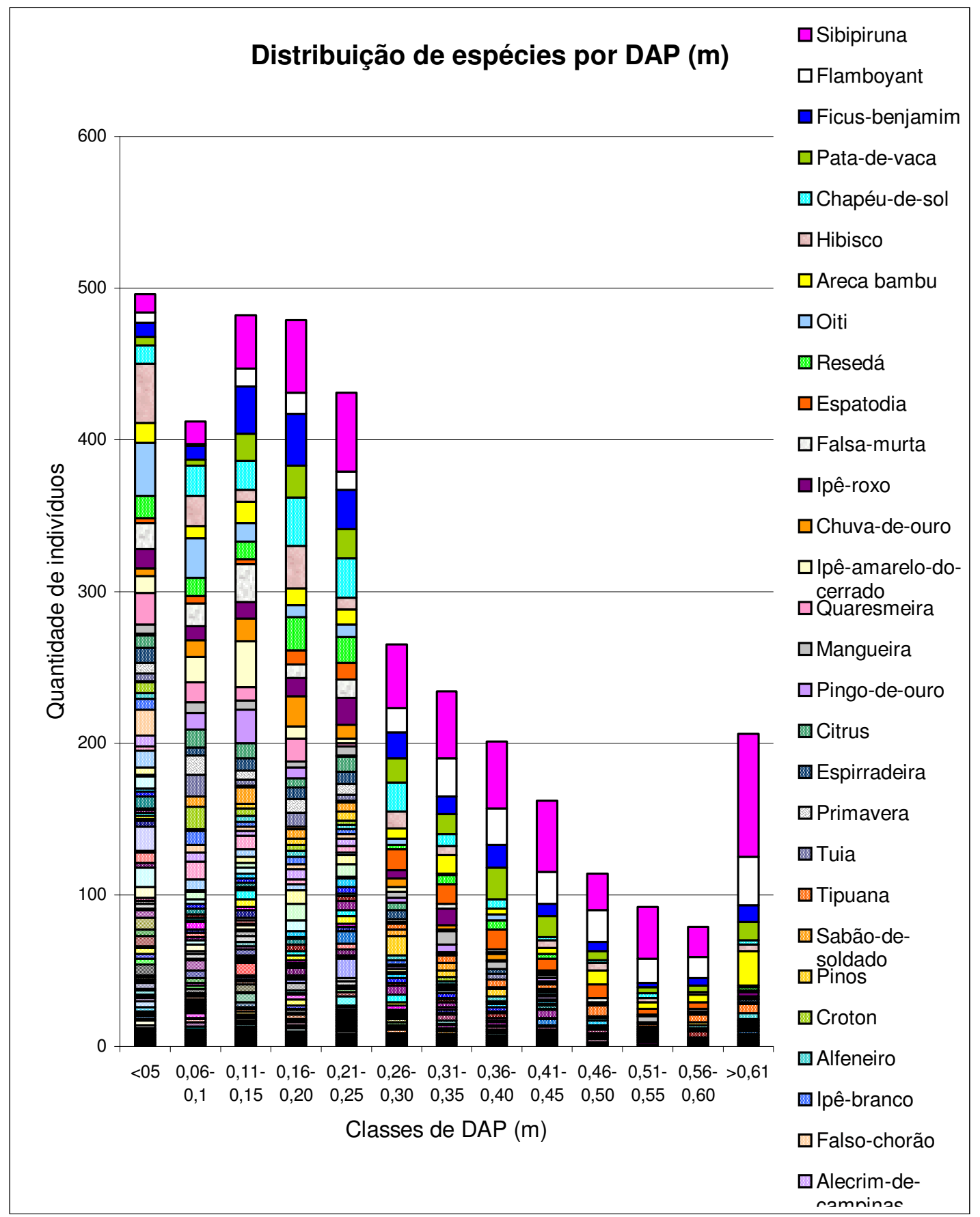

Figura 3 - Distribuição das principais espécies segundo classes de diâmetro à altura do peito (DAP) e quantidade de indivíduos, em ordem de freqüência na arborização viária da Estância de Águas de São Pedro-SP

Em relação à tendência de plantio de espécies arbustivas, com altura inferior a um metro, observa-se a predominância de pingo-de-ouro com freqüência de $18,06 \%$, seguida de hibisco com 14,58\%. Em relação à distribuição dos indivíduos com altura inferior a dois metros, observa-se a predominância do hibisco com 13,46\%, seguido de falsa-murta com 
6,52\%, areca-bambu com 5,67\%, pingo-de-ouro com 5,67\%; reforçando a ocorrência do maior plantio de espécies arbustivas ao invés de arbóreas, fator preocupante ao município.

Durante o levantamento, houve muitas manifestações por parte da população, a respeito da autoria dos plantios em calçadas, o que sem dúvida, contribuiu para o incremento da diversidade e do número de indivíduos na estância; porém, não contribui para a composição paisagística do local, gerando falhas na plasticidade, entre outros problemas. Fica, então, patente a necessidade do setor público interferir, seja orientando a população, seja regulamentando essa prática.

\section{Índices de diversidade}

Para o índice de riqueza ou variedade, denominado Odum, que usa apenas o número total de espécies e o somatório das abundâncias de indivíduos em uma comunidade (Coelho, 2000), obteve-se o valor de 19,50 para a Estância de Águas de São Pedro. Já na cidade de Jaboticabal, o índice encontrado foi de 12,98 (Silva-Filho et al., 2002).

No que se refere ao índice de Shannon-Wiener (Coelho, 2000), que parte do pressuposto que as espécies têm abundâncias diferentes, foi obtido o valor de 3,90 para a arborização viária da Estância de Águas de São Pedro. Enquanto que para a Orla de Santos, obteve-se um índice de 2,63 (Menegueti, 2003).

Observa-se que esses dois índices, são comparativamente maiores aos encontrados em outras cidades, apresentando-se bem superiores (Silva Filho, 2002). Porém, isso não quer dizer que a estância possui uma diversidade ideal, pois nota-se o alto índice de arbustos e de espécies que não são indicadas para a arborização viária. Nota-se a necessidade de mais pesquisas relacionadas ao assunto, a fim de se obter indicações de índices mínimos e máximos desejáveis para área urbana.

\section{CONCLUSÕES}

A arborização viária da Estância de Águas de São Pedro possui 161 espécies, 126 gêneros e 54 famílias. A maioria das espécies catalogadas é exótica. Possui uma elevada densidade de indivíduos, o que não a qualifica. Há uma tendência de plantio de espécies arbustivas, que deve ser revertida, pois não proporciona melhorias ambientais e é preocupante ao município; sendo necessária a intervenção do setor público em vários aspectos. 


\section{REFERÊNCIAS BIBLIOGRÁFICAS}

ÁGUAS DE SÃO PEDRO. WWW.AGUASDESAOPEDRO.SP.GOV.BR (15 MAR. 2004).

ALVAREZ, I.A.; LIMA, A.M.L.P.; FREIRE, H.B.; RIBEIRO, R.C.S. Desempenho ecológico: uma proposta para a avaliação da vegetação urbana (compact disc). In: CONGRESSO BRASILEIRO DE ARBORIZAÇÃO URBANA, Belém, 2003. Resumos. Belém: UFPA, 2003.

COELHO, R.M.P. Fundamentos em ecologia. Porto Alegre: Artes Médicas Sul, 2000. 247p.

IBGE - Instituto Brasileiro de Geografia e Estatística, STATCART - Base de informações por setor censitário, Estância de Águas de São Pedro, SP - Censo Demográfico 2000. Rio de Janeiro, RJ, 2002. 1 CD-ROM.

LOMBARDO, M.A. Vegetação e clima. In: ENCONTRO NACIONAL SOBRE ARBORIZAÇÃO URBANA, Curitiba, 1990. Curitiba: FUPEF, 1990. p.1-13.

MENEGUETTI, G.I.P. Estudo de dois métodos de amostragem para inventário da arborização de ruas dos bairros da orla marítima do município de Santos-SP. Piracicaba, 2003. 100p. Dissertação (Mestrado) - Escola Superior de Agricultura "Luiz de Queiroz", Universidade de São Paulo.

MILANO, M.S.; DALCIN, E. Arborização de vias públicas. Rio de Janeiro: Light, 2000. $206 p$.

PAIVA, H.N. de; GONÇALVES, W. Florestas urbanas: planejamento para melhoria da qualidade de vida. Viçosa: Aprenda Fácil, 2002. 177p. (Série Arborização Urbana, 2).

RACHID, C. Estudo da eficiência de dois métodos de amostragem de árvores de rua na cidade de São Carlos - SP. Piracicaba, 1999. 99p. Dissertação (Mestrado) - Escola Superior de Agricultura "Luiz de Queiroz", Universidade de São Paulo.

SANTAMOUR JÚNIOR, F.S. Trees for urban planting: diversity unifomuty, and common sense. Washington: U.S. National Arboretum, Agriculture Research Service, 2002.

SANTOS, N.R.Z dos; TEIXEIRA, I.F. Arborização de vias públicas: ambiente $\mathbf{x}$ vegetação. Santa Cruz do Sul: Instituto Souza Cruz, 2001. 135p. 
SÃO PAULO (Estado). Secretaria do Meio Ambiente. Manual ambiental: princípios da recuperação vegetal de áreas degradadas. São Paulo: SMA;CEAM;CINP, 2000. 76p

SILVA FILHO, D.F. da. Cadastramento informatizado, sistematização e análise da arborização das vias públicas da área urbana do município de Jaboticabal, SP. Jaboticabal, 2002. 81p. Dissertação (Mestrado) - Faculdade de Ciências Agrárias e Veterinárias, Universidade Estadual Paulista “Júlio de Mesquita Filho".

SILVA FILHO, D.F. da; PIZETTA, P.U.C.; ALMEIDA, J.B.S.A. de; PIVETTA, K.F.L.; FERRAUDO, A.S. Banco de dados relacional para cadastro, avaliação e manejo da arborização em vias públicas. Revista Árvore, v.26, n.5.p.629-642, 2002. 